\title{
A STUDY OF BODY MEASUREMENTS OF SPORTY AND NOT SPORTY PERSONS LIVING IN PÄRNU COUNTY
}

\author{
Kandela OUnN ${ }^{1}$, Kaisa KIRIKaL ${ }^{2}$ \\ ${ }^{1}$ Research Centre of Pärnu College of the University of Tartu, Pärnu, Estonia \\ ${ }^{2}$ Sports Union of Pärnu County, Pärnu, Estonia
}

\begin{abstract}
In 2019, a study was conducted on athletic activity among the inhabitants of Pärnu County. 1446 respondents aged 15-87 years participated in the study. The respondents were divided into two groups according to their athletic activity - respondents who are at least lightly active (named as SPORTY, $\mathrm{n}=1244$ ) and respondents with no sport activity (NOT SPORTY, $\mathrm{n}=202$ ). $41 \%$ of respondents had been engaged in physical activity for 10 years or more. A "not sporty" respondent is a person with a slight tendency to overweight, rather not satisfied with his/her health but quite satisfied with his/ her life and is short of time to work out but would like to engage in cycling, swimming or hiking. The "sporty" person's body mass index is normal, and he/she has been engaged in sports for at least 10 years to achieve better physical fitness or well-being. He/she enjoys walking, cycling, or running. Women prefer group training; men prefer to train in the gym on their own. Respondents with more than five years of regular physical activity work out every week somewhat longer than others and, on average, a few hours more per week in summertime than in autumn and spring. Sporty respondents tend to be taller and of medium weight.
\end{abstract}

Keywords: somatotypes; SD-classes; height; weight; BMI; sporty; not sporty

\section{INTRODUCTION}

There are many risks of cardiovascular disease which is one of the most prevalent causes of death in the world and also in Estonia, and it is necessary to focus much more effectively on promoting health behaviour, including increasing physical activity among the Estonian population [8]. Surveys conducted in 2013 
and 2014 show that the proportion of people regularly exercising in Estonia ranges from $36 \%$ to $39 \%$ [9]. The proportion of overweight persons (body mass index over $25.0 \mathrm{~kg} / \mathrm{m}^{2}$ ) was $57.9 \%$ and $52.0 \%$ in males and females respectively [9], and its increase has been especially noticeable in the last decade [8].

According to the WHO Guidelines [10], adults (18-64 years) should be physically active at least 150 minutes per week (preferably on five days of the week) with moderate intensity or 75 minutes per week (three times per week) with high intensity. Data from studies show a clear global downward trend in motor activity, which has led to the introduction of the term "physical inactivity pandemic" [4].

In 2015 Children's Movement Survey was conducted to map children's movement activity. Every autumn, the Estonian Olympic Committee (EOK) in cooperation with Sport for All conducts a survey [1] on physical activity in the population. In Pärnu, a health survey of the city of Pärnu was conducted in 2016 [6], and, based on this, the health profile of the city of Pärnu was compiled in 2017. It also briefly explored the movement patterns of the population. It was necessary to map the physical activity of inhabitants in Pärnu for further political decisions to improve the planning of facilities for being more active and living a healthy life. This article focuses on the body measurements (height and weight) gathered in the survey "Physical activity habits of Pärnu County population". The study report [5] did not analyse specifically the relationship between physical activity and body size, but it is interesting to analyse how height-weight classes [2;7] and somatotypes are distributed among sporty and not sporty persons in Pärnu County.

\section{MATERIAL AND METHODS}

The questionnaire of this study is based on the Estonian Olympic Committee survey, which was supplemented with more detailed information on sports activities in cooperation with Pärnu County Sports Union. The target group of the survey were the residents of Pärnu County aged 15-70 years. The data were collected from early March to mid-April 2019. The sample of the survey consists of people living in Pärnu County (99\% Estonians and 46\% residents of Pärnu who lived in the city, not its subdivisions), and the final sample size was 1446 respondents. Mostly women (76\%) participated in the survey, with fewer respondents than expected in the 20-24 years age group. In terms of education and family status, the distribution of the sample is similar to the population of Pärnu county. The highest proportion of respondents live in households with 
two members (57\%, see Figure 2) and no minor children (45\%). 63\% of the respondents work and $22 \%$ receive an income similar to the Estonian average income.

\begin{tabular}{|c|c|c|c|c|}
\cline { 3 - 5 } \multicolumn{1}{c|}{} & \multicolumn{3}{c|}{ Weight classes } \\
\cline { 2 - 5 } \multicolumn{1}{c|}{} & Light & Medium & Heavy \\
\cline { 2 - 5 } & Short & 1. Small & $\begin{array}{c}\text { 5. Pyknomorphic } \\
\text { I }\end{array}$ & II \\
\hline \multirow{3}{*}{$\begin{array}{c}\text { Height } \\
\text { Classes }\end{array}$} & Medium & $\begin{array}{c}\text { 4. Leptomorphic } \\
\text { I }\end{array}$ & 2. Medium & III \\
\cline { 2 - 5 } & Tall & II & III & 3. Large \\
\hline
\end{tabular}

Figure 1. Body build classes [3]

In this study, the sports activity level was included. Respondents $(\mathrm{n}=1202)$ who had both height and weight data were considered from the pooled data to compare somatotypes.

\section{RESULTS AND DISCUSSION}

\section{Physical activity of respondents}

Based on the survey report, the authors first describe the respondents' attitudes towards healthy sport and their association with physical activity. $84 \%$ of respondents are very interested or quite interested in healthy sports, but $14 \%$ have never done regular exercise and $41 \%$ have done it for over ten years. There were no differences between the males and the females. Regarding to the relationship between attitudes and physical activity in healthy sports, we can say that the interest in recreational sports is significantly higher among sporty respondents, namely $70 \%$ of those who are not interested in sports, have reported no physical activity they can name as sport. From respondents who had difficulties to express their interest in healthy sports $50 \%$ are not engaged in physical activity. At the same time, several respondents who are not interested in healthy sports but have been engaged in physical activity for more than five years can also be found in the sample. There are no big differences between men and women. There are $10 \%$ women and $5 \%$ men who are quite interested in healthy sport but do not exercise. 
Based on the collected data, it can be said that a not sporty respondent is rather slightly overweight, mostly due to lack of time for being engaged in physical activity (63\% consider this reason to be quite or very important), would like to cycle (68\%), swim (53\%) or hike (50\%). They are either rather satisfied (41\%) or rather dissatisfied (35\%) with their health, generally more satisfied with life (54\%), most often satisfied with their sleep time (39\%), do not consume alcohol (68\%) and do not smoke too much (77\%); 60\% mostly or always eat breakfast every morning, but are doubtful about their nutrition awareness (55\%).

The sporty respondent has a normal physique (both women and men have a BMI of less than 25 and up to 2 units lower than not sporty respondents), the female sporty respondents weigh on average $67 \mathrm{~kg}$ and the male sporty respondents weigh $82 \mathrm{~kg}$ ( $4 \mathrm{~kg}$ and $7 \mathrm{~kg}$ lighter than not sporty respondents, respectively); on average, they are four years older (males 36 years, females 38 years) than not sporty respondents.

$\mathrm{He} /$ she has been exercising regularly for more than ten years and does so because he/she wants to be fit ( $90 \%$ considered it very or quite important), feel good (97\%) and has good sports facilities close to his/her home (74\%). He/she rather does not care about participating in public sporting events (32\%), practising sport with friends (48\%) and the benefits or advantages allocated by the workplace for sports (45\%). The sporty respondent walks (with or without poles) ( $44 \%$ do it $2-3$ or more than 4 times a week) on roads or streets ( $74 \%$ mostly or always) or on cycling and pedestrian paths (71\%) or rides a bike more than 2-3 times a week $(35 \%)$ om roads or streets $(81 \%)$, on cycling and pedestrian paths (75\%) or on health trails specially designed for physical activity (50\%).

On average, it takes 10 hours per week to play sports in summer, 8 hours in spring and autumn and 6 hours in winter. In summer, the sporty respondents exercise usually or only outdoors (82\%), in autumn and spring, indoors and outdoors (37\%) and, in winter, mostly indoors (34\%). Most frequently they work out either on their own (37\%) or a with coach (24\%); they consider their workout volume either more or less or completely sufficient (69\%); 55\% want to sport somewhat more than they do now, and they think that more all-theyear-round sport events are needed (34\%). $38 \%$ of sporty respondents have not participated in any popular sporting event; they consider their health good (65\%), are rather satisfied with their life (66\%), have sufficient sleep time (51\% agree or agree completely); they do not consume too much alcohol (53\% agree completely) or smoke ( $84 \%$ agree completely), eat every morning (50\% agree completely), but their emphasis on informed nutrition is average (this way or that $47 \%$, agree $31 \%$ ). 
Figure 2 shows which fields of sport are practised and how often.

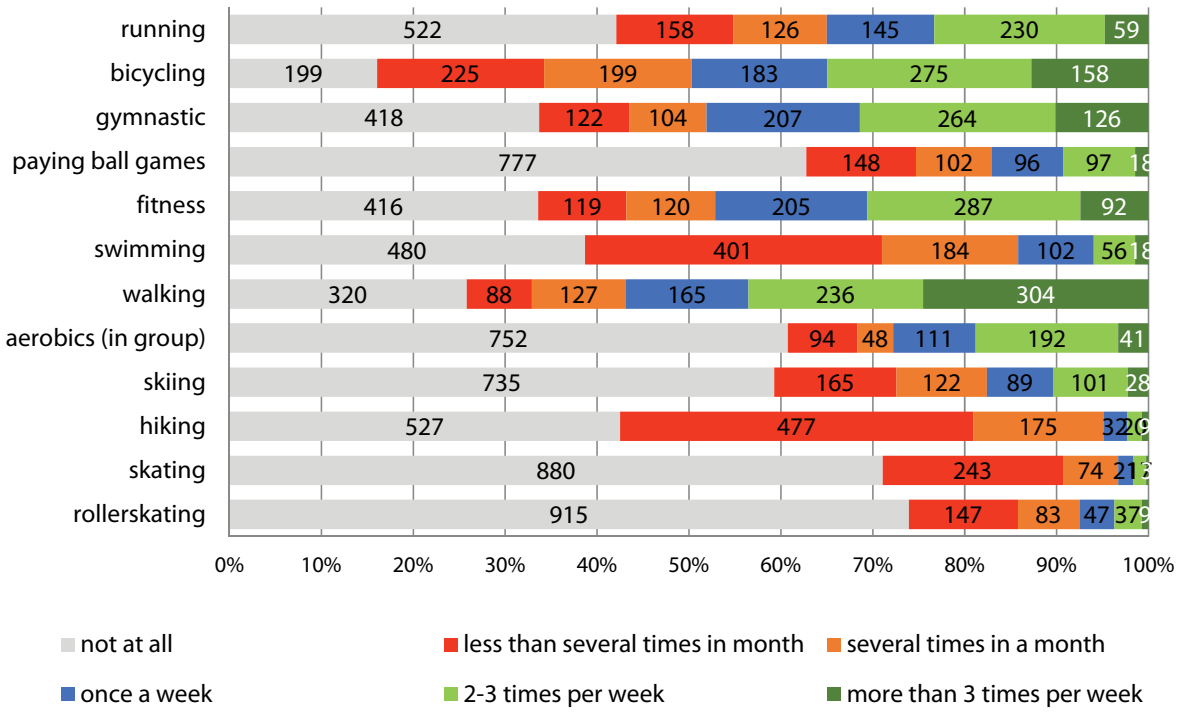

Figure 2. Mobility hobbies practised by sporty respondents $(n=1244)$

Based on the respondents' answers, it turns out that six fields are most often practiced from among the 12 fields offered in the questionnaire (17\%, see Figure 3), but usually they practise 2-3 fields more than once a week.

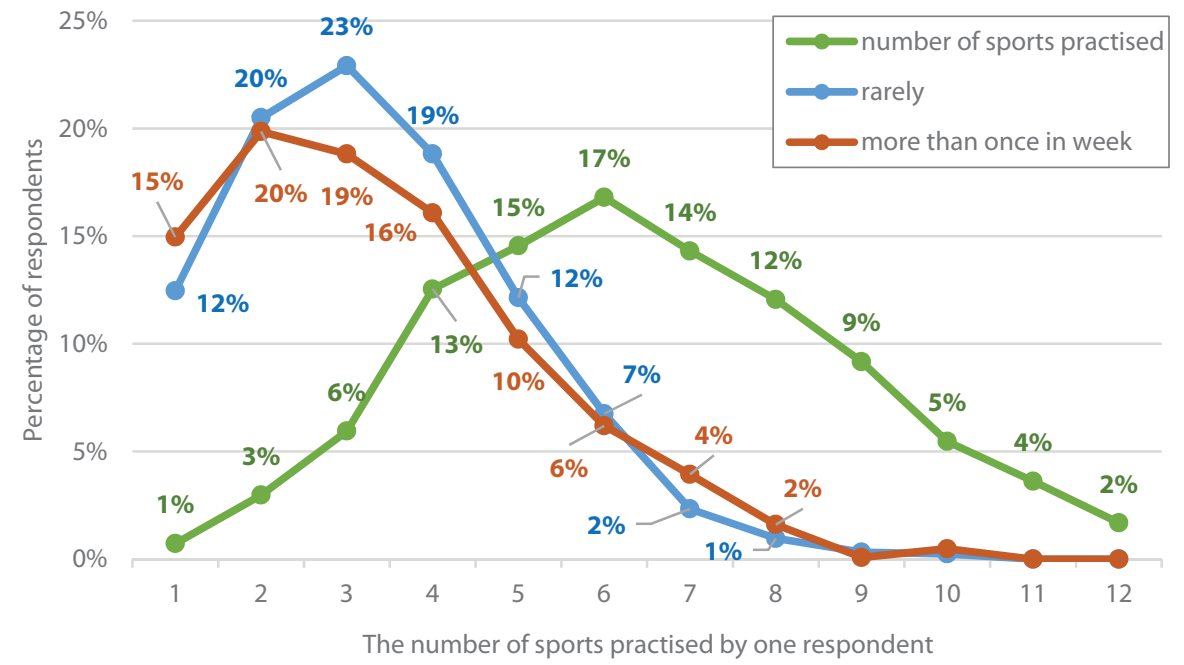

Figure 3. Number and intensity of engaging in different sports. 
Walking, cycling, gymnastics and strength training as lower intensity sports are usually practiced in combinarion by one person, but if the respondents practice higher intensity sports, they usually practice in two or three areas, such as running, cycling and strength training. It can be concluded that those who are more serious about physical activity are focused on a smaller number of areas, but those who are engaged in more areas are more likely just having fun. In most cases, exercise is practiced longer and outdoors during warmer and drier weather, and indoors and for shorter periods when weather is colder, darker, and wetter. This trend was also confirmed by the results of the present study. If we compare the duration of physical activity per week in different seasons (see Figure 4), it can be said that the respondents who have been engaged in physical activity for more than five years do it somewhat longer per week each season than the respondents who have been exercising less than one year. In summer, from June to August, everyone moves a few hours more than in winter. Gardening and lawn mowing, which can be done in summer, were also often mentioned as a part of physical activity.

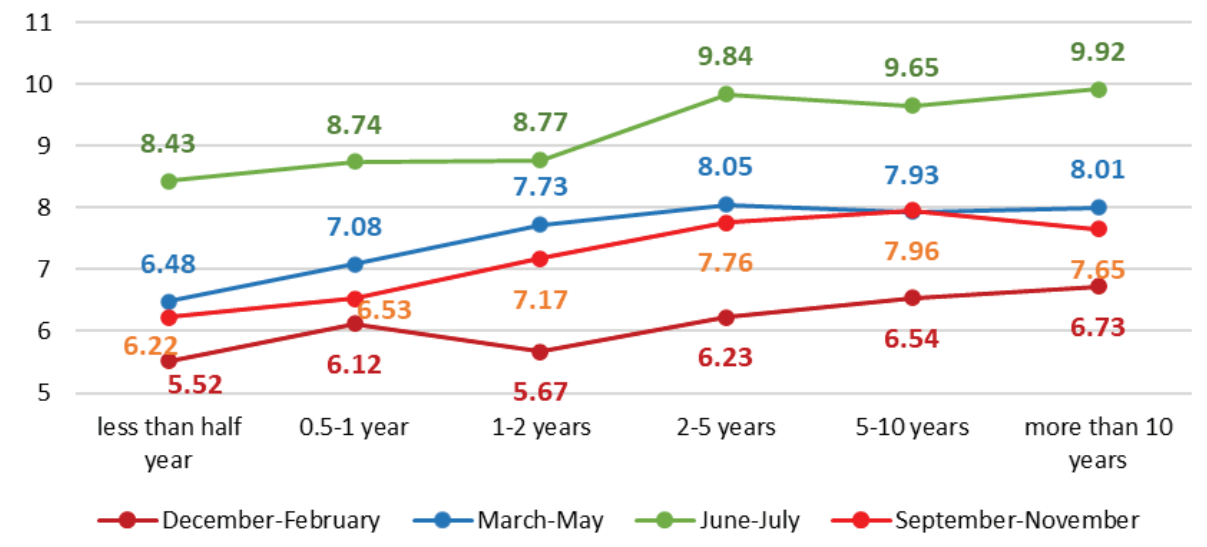

Figure 4. Average number of hours of physical activity per week in different seasons by duration of activity.

In general, it can be said that people overestimated their movement time during the week (this is also a common problem according to Tali and Unt [8]), and to check the accuracy of the data, the method of statistical standardization was used, and it showed that $20 \%$ higher values (in summer more than $30 \mathrm{~h}$ and in other seasons over 26h) were not in line with the rest of the answers. These $20 \%$ of responses were marked as missing values in the analysis. The respondents were also allowed to comment on their answers, and it appeared 
that respondents who marked longer hours often classified everyday activities and activities, such as gardening and housework, as physical activities.

\section{Body types and sports activity}

The sample collected is mostly based on sporty respondents, although it includes 35 men ( $11 \%$ of men) and 125 women ( $14 \%$ of women) who say they do not sport at all (see Figure 5). This distribution is due to the title of the survey, which probably invited more sporty persons to open the questionnaire and fill it than not sporty people. The number of women respondents is proportionally higher since women are often more likely than men to respond to surveys. As somatotypes were defined separately for each respondent's height and weight and according to the height and weight norms developed based on Estonians, the disproportion of the present data by gender and sports activity is not an obstacle.

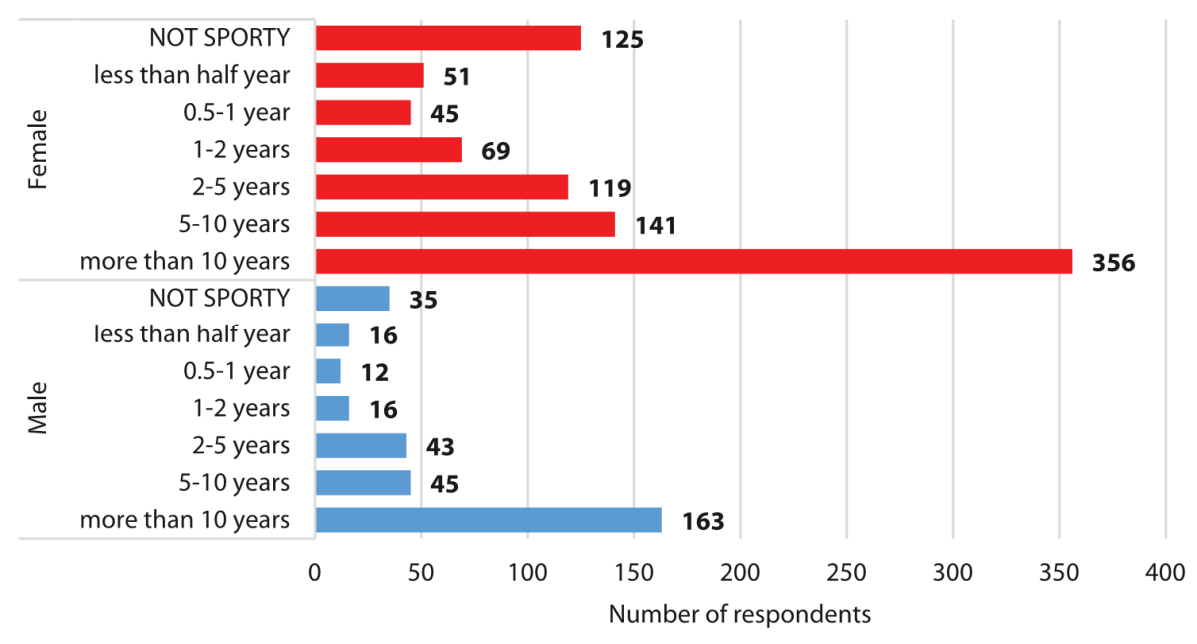

Figure 5. Distribution of men and women by time spent on sport activity.

Respondents were divided into two groups (sporty and not sporty) and sporty respondents into six groups according to their regular physical activity (see Table 1), and their descriptive statistics on body weight, height and BMI were calculated. 


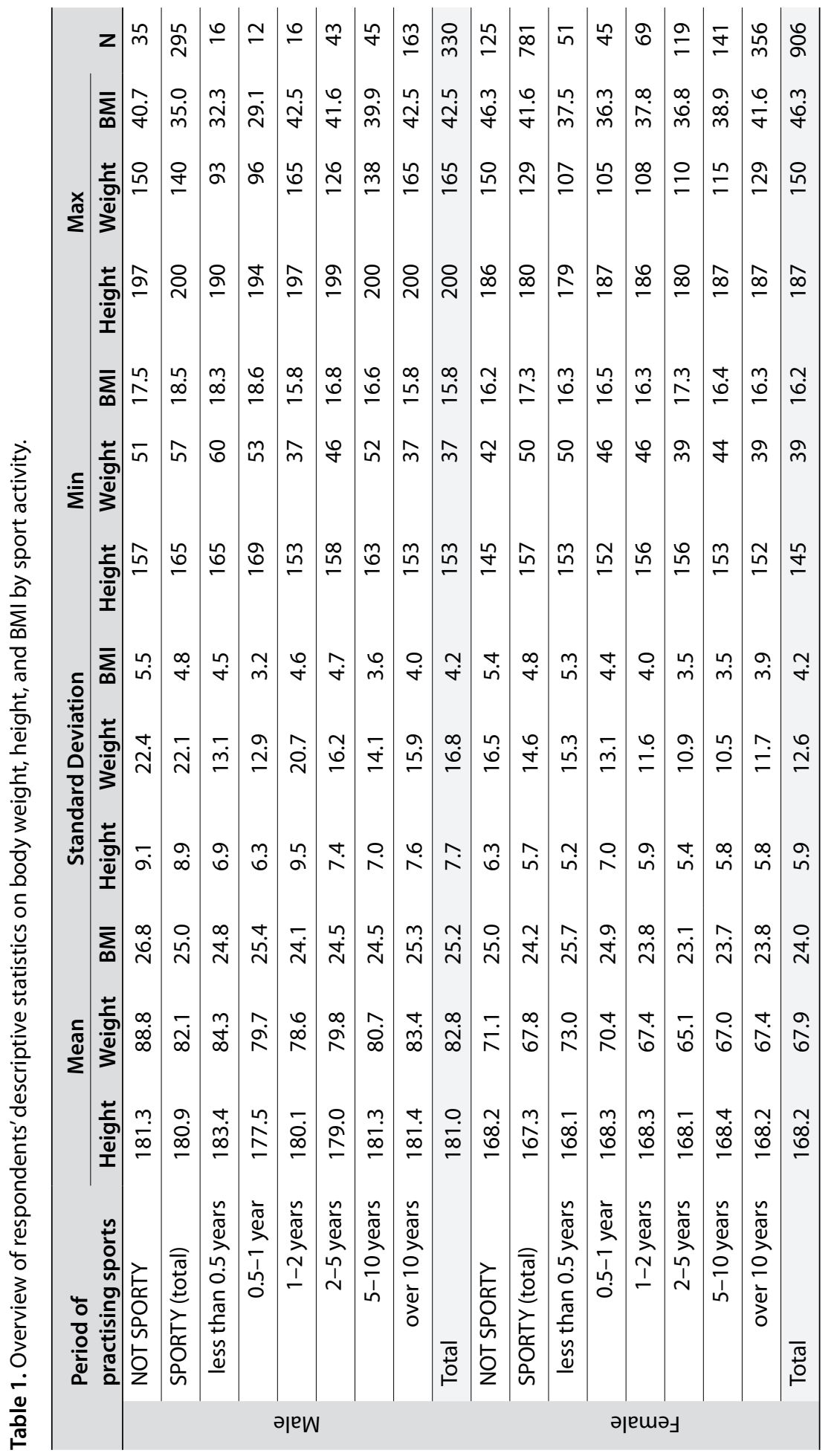


Firstly, the height and weight SD-classes distribution was calculated (see Figure 6) for male and female respondents.
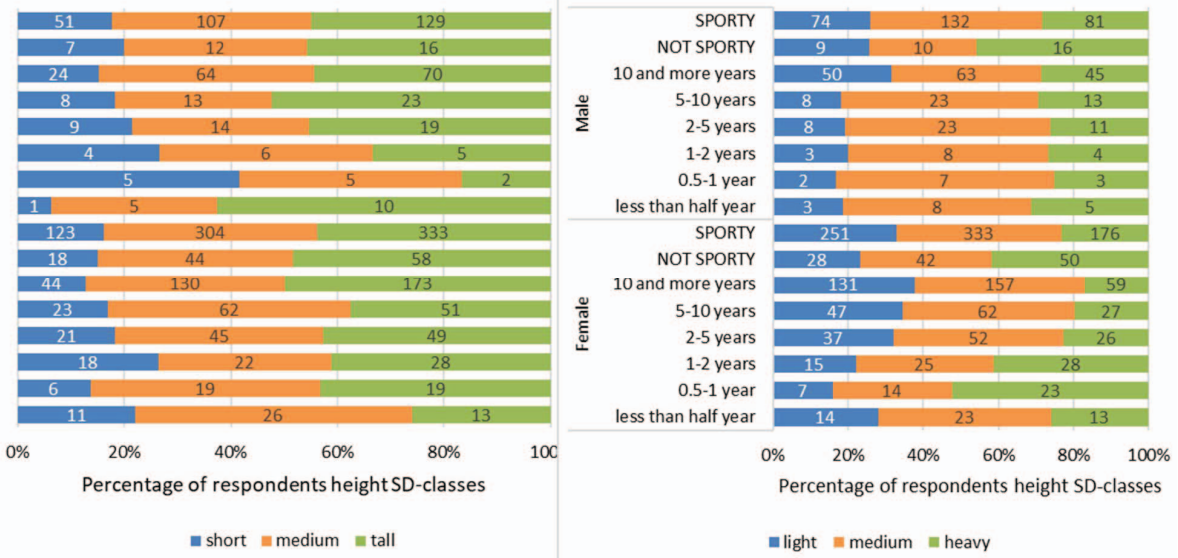

Figure 6. The number and percentage of male and female respondent's height and weight SD-classes by sports activity.

In terms of height, although there are no differences in somatotypes between sporty and not sporty respondents for either men or women, there is a positive correlation among men - taller men have longer been involved in sport activities than shorter men, but this is a random result, as there are not many respondents among those who have been involved in sports for a shorter period of time. In terms of weight, one can see that among female respondents who have been engaged in sports for a longer period, there are more respondents with lower weight than among those who have done less sports. This difference does not stand out so well for men, but probably the reason is that there were few (35) not sporty respondents, and half of the men who have been doing sports have been doing so for more than 10 years.

There are several ways to analyse body types by height and weight, and Figure 7 presents the results based on the nine body type method developed by Kaarma and co-authors [2]. 


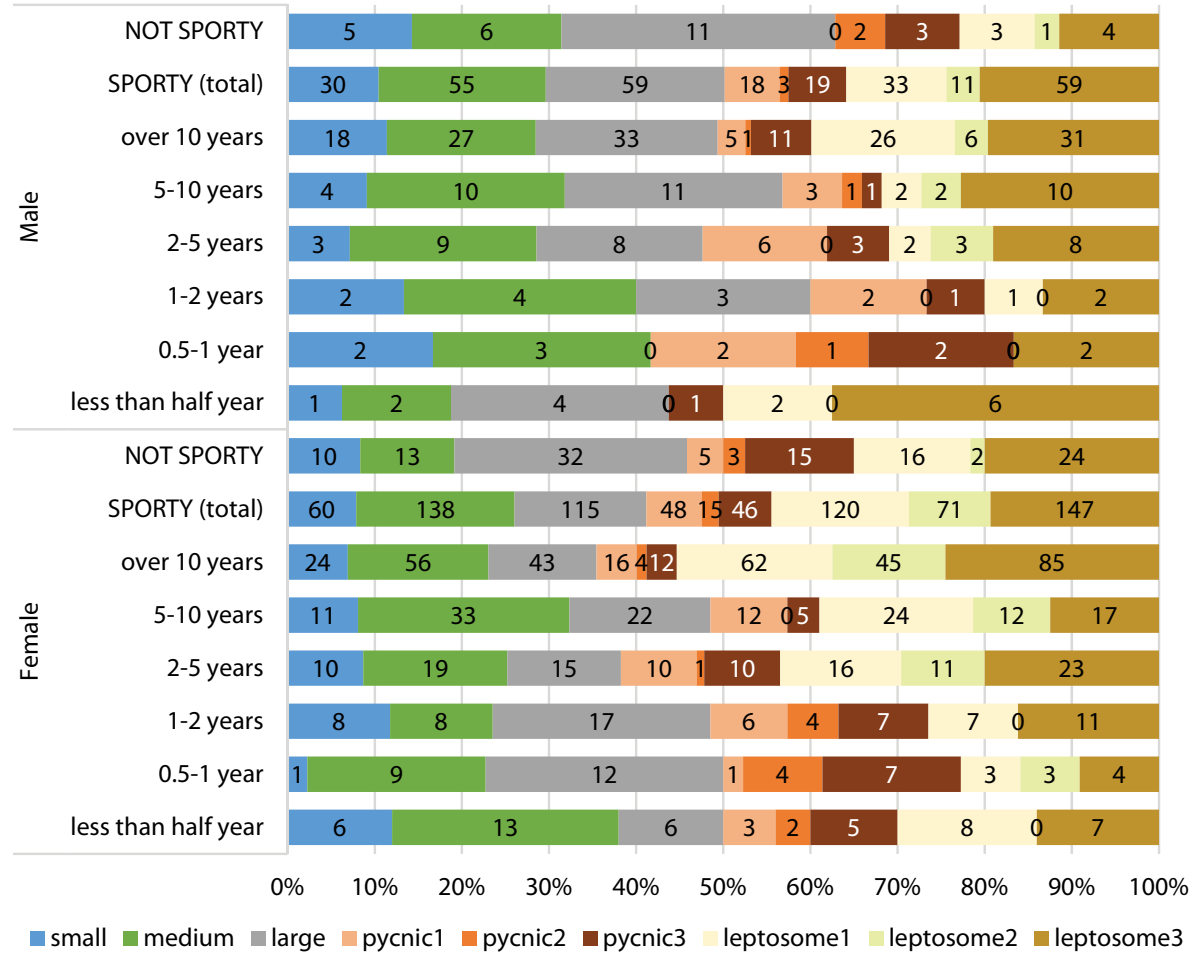

Figure 7. The number and percentage of male and female respondents' body types by sports activity

Sporty males have more often leptosome 3 body type than not sporty males ( $20 \%$ vs $11 \%$ ). That means that the sporty men are medium by weight and tall by height. Among not sporty men there is a higher percentage of the large body type ( $31 \%$ of not sporty men), and that is $1 / 3$ bigger percentage as the same number among sporty male respondents. The same difference also appears between sporty and not sporty female respondents, but sporty females tend to belong to the medium body type class (35\% of sporty female respondents). Considering the small number of respondents who had been practising sports less than half a year before the study, it is not possible to compare the body types among these groups. Male respondents who had practised sports for less than last 2 years tend to belong to the medium or large body type classes, those who had been engaged in sports for 2-5 years are mostly large or leptosome 3 by body type. So, they are as tall but lighter than the men who had been sporty for a shorter time. Sporty females who were active $0.5-2$ years are mostly large ( $27 \%$ of both groups) and females active for more than 2 years are of medium 
or leptosome 3 body type. So, the trend is similar for men and women. The smallest number of sporty respondents is from the pycnomorphic body type (short but medium or heavy by body weight). Females with activity time of more than 10 years have the biggest number of leptomorphic 1 and 2 body types (medium or tall by height but light by weight).

In conclusion, most studies in health areas confirm that being physically active is good for your health. This study also did not show the opposite result, but it was interesting to analyse how body types accord with physical activity. The results confirmed that sporty respondents have less weight than not sporty respondents, sporty respondents who had been active for more than 5 years are taller and lighter (mostly leptomorphic 3 body type) than those who had been active for less than 5 years (mostly medium body type). It also is interesting that by height SD classes about $40 \%$ of respondents were tall but by weight SD classes approximately $50 \%$ were medium.

\section{REFERENCES}

1. EOK (2018). Eesti elanike kehaline aktiivsus. https://media.voog. com/0000/0041/2571/files/2018 Eesti elanike kehaline aktiivsus kokkuvõte.pdf

2. Kaarma H., Veldre G., Saluste L., Lintsi M., Kasmel J., Tiit E.-M., Stamm R., Toomsalu M., Arend A. (2017). On systematisation of Estonians' body build data. Papers on Anthropology, 26(1), 9-27. https://doi.org/10.12697/poa.2017.26.1.01

3. Kaarma H., Veldre G., Saluste L., Lintsi M., Kasmel J., Tiit E.-M., Stamm R., Toomsalu M., Salm E., Käärik E., Arend A. (2018). Height-weight classification of Estonian schoolchildren aged 7-18 years. Papers on Anthropology, 26(1), 17-24. https://doi.org/10.12697/poa.2018.27.1.02

4. Kohl H.W., Craig C.L., Lambert E.V., Inoue S., Alkandari J.R., Leetongin G., Kahlmeier S. (2012). The Pandemic of Physical Inactivity: Global Action for Public Health. The Lancet, 380(9838), 294-305. https://doi.org/10.1016/S0140-6736(12)60898-8

5. Õun K. (2019). Pärnumaa elanike liikumisharjumused ja -hoiakud. https://www.psl.ee/wp-content/uploads/2019/05/Pärnumaa-liikumisuuring-1.pdf

6. Õun K., Übner M., Mägi M. (2017). Pärnu linna täiskasvanud elanike terviskäitumise uuring 2016. aastal. https://parnu.ee/failid/uuringud/P2rnu_linna_elanike_tervisek2itumise_uuring2017.pdf

7. Raschka C. (2018). On the importance of the Estonian constitutional typing system for sports anthropology. Papers on Anthropology, 27(2), 9-15. https://doi.org/10.12697/poa.2018.27.2.01 
8. Tali M., Unt E. (2016). Eesti elanikkonna kehaline aktiivsus: soovituste täitmine ja seosed ülekaalulisusega. Sport ja Liikumine, 12, 26-35. https://media.voog.com/0000/0041/2571/files/Ajakiri 12 2016.pdf

9. Tekkel M., Veideman T. (2015). Health Behavior among Estonian Adult Population. https://intra.tai.ee/images/prints/documents/14274488161_T2iskasvanud_rahvastiku_tervisek2itumise_uuring_2014.pdf

10. World Health Organization (2018). ACTIVE: A Technical Package for Increasing Physical Activity. https://apps.who.int/iris/handle/10665/275415

\title{
Address for correspondence:
}

\author{
Kandela Õun \\ Pärnu College \\ University of Tartu \\ Ringi 35, Pärnu, 80011, Estonia \\ E-mail: kandela.oun@ut.ee
}

